\title{
A Política Externa Independente em ação: a Conferência de Punta del Este de 1962
}

\author{
Independent Foreign Politics in Action: An Overview \\ of the Punta del Este Convention in 1962
}

HÉLIO FRANCHINI NETO*

Rev. Bras. Polít. Int. 48 (2): 129-151 [2005]

\section{Introdução ${ }^{1}$}

Em 22 de janeiro de 1962, Ministros das Relaçôes Exteriores dos Estadosmembros da Organização dos Estados Americanos (OEA) reuniram-se sob os auspícios do Tratado Interamericano de Assistência Recíproca (Tiar) para considerar "as ameaças à paz e à independência política dos Estados Americanos" 2 . A Conferência focava-se na situação política do governo de Cuba, cujo líder - Fidel Castro - declarara adesão ao marxismo-leninismo, e nas alegadas ações contra países vizinhos. Após dez dias de discussões, em 31 de janeiro, Cuba foi suspensa da Junta Interamericana de Defesa e da OEA, sendo que esta última decisão não contou com votos favoráveis dos maiores Estados latino-americanos. Desde então, as decisões da VIII Reunião são debatidas por políticos, diplomatas e estudiosos da ciência política, sem, todavia, procederse a análise pormenorizada. Em certo sentido, continua sem resposta a pergunta do embaixador Teixeira Soares (1980: 154): "que mérito teve a Conferência de Punta Del Este?”.

O problema cubano representou capítulo determinante das relações hemisféricas. Nele, incluía-se o tratamento de temas como as relações Estados Unidos - América Latina, a solidariedade continental, o problema do comunismo e o princípio da não-intervenção. O sistema interamericano, representado pelo Tiar e pela OEA, foi obrigado a lidar, de um lado, com a possibilidade de instalação de modelo de governo fundamentado em ideologia distinta daquela do bloco

\footnotetext{
* Diplomata, mestre em Ciência Política pela Universidade de São Paulo - USP (helio@mre.gov.br). O presente artigo reflete apenas as opiniōes pessoais do autor e não busca representar as posições oficiais do governo brasileiro.

${ }^{1}$ Este artigo é extensivamente baseado na dissertação de mestrado do autor, apresentada ao Programa de Pós-Graduação em Ciência Política da Universidade de São Paulo, em novembro de 2004.

2 Ata final da VIII Reunião de Consultas dos Ministros das Relações Exteriores Americanos.
} 
ocidental, sem ferir princípios da não-intervenção ou mesmo da autodeterminação (citado, por exemplo, por Roberto Campos em suas memórias); de outro, com uma revolução que patrocinava guerrilhas pelo continente, além da ameaça (ainda que improvável), de intervenção extracontinetal, sem que se estabelecesse o precedente de intervenção em Estados americanos.

Nesse intrincado jogo de interesses que dividiu as repúblicas americanas, teve destaque a posição brasileira. A delegação, liderada por Francisco Clementino de San Tiago Dantas, opôs-se às sanções contra Cuba e, junto com Argentina, México, Chile, Bolívia e Equador, absteve-se da resolução que suspendia o governo cubano da OEA. San Tiago Dantas tornou-se uma das principais figuras da reunião, defendendo firmemente a inoperância e ilegalidade de sanções, cujo resultado (na visão de San Tiago), seria a consolidação da influência soviética.

A Conferência de Punta Del Este, ao mesmo tempo, teve grande repercussão na política brasileira. Poucas vezes a opinião pública brasileira mobilizou-se em assuntos de política internacional como o fez em janeiro de 1962. Nas palavras de Alceu Amoroso Lima (1962), em artigo da época: "[...]Tenho, como todo mundo, o pensamento voltado para Punta Del Este. Ali começa hoje (quando escrevo essas linhas), a jogar-se o destino da instituição internacional mais antiga dos nossos tempos: a Organização dos Estados Americanos, órgão do pan-americanismo, idealizado por Bolívar em 1826, e laboriosamente edificado em quase século e meio de ingentes esforços".

Se não há dúvida da importância da reunião de Punta para as relações hemisféricas em geral, e para a política externa brasileira em especial, permanecem pouco estudadas as razões que levaram o governo brasileiro a se posicionar da forma como o fez em 1962. Muitos autores comentaram-nas brevemente, mas ainda restam algumas perguntas a serem respondidas: "a posição brasileira fundou-se apenas em defesa do respeito às regras da OEA? Quais as razóes políticas para esse ponto de vista? Por que o Brasil se absteve e não votou contra a suspensão? Qual a relevância de Punta para a política externa brasileira? Tratou-se de exemplo de ação da 'política externa independente'”?

O objetivo do presente trabalho é apontar elementos que permitam compreender as razões pelas quais o governo brasileiro tomou a decisão de abster-se na VIII Reunião de Ministros das Relações Exteriores, à luz de sua relação com os Estados Unidos e a América Latina, em meio à Guerra Fria. Como se verá, a VIII RMRE constituiu um ponto de convergência entre desdobramentos da Guerra Fria na América Latina, e projetos e constrangimentos específicos da política brasileira; tem-se, dessa forma, a possibilidade de se verificar como o país lidou com um problema de política externa, mas que afetava diretamente os desenvolvimentos internos, as pressóes e os limites de uma atuação internacional dentro de um sistema específico. 


\section{A conjuntura internacional}

\section{Guerra Fria e a América Latina}

Em janeiro de 1962, a Guerra Fria - e a estrutura internacional decorrente da confrontação bipolar - já definira contornos específicos à realidade internacional, que se desenvolveram especialmente a partir de 1947. Existem divergências quanto ao momento de seu início, mas autores como Aron (1975) e Walker (1993), dentre outros, destacam 1947 como o ponto em que a disputa adquire contornos mais claros. Aron (1975: 74), destaca que o termo deve ser entendido como a fase de tensão entre os aliados (que combatiam o Nazismo), que se desenrola desde o fim da Segunda Guerra Mundial e que adquire contornos mais nítidos em 1947, com a Doutrina Truman; a ruptura aprofunda-se na Conferência de Paris, na discussão do Plano Marshall, e com a situação dos países da Europa Oriental. A partir desses episódios, resumidamente, a confrontação amplia-se em casos como o Bloqueio de Berlim, em 1948, com a bomba soviética e a vitória do comunismo na China, em 1949.

A Guerra da Coréia ampliou o campo de confrontação bipolar para além da Europa: "foi o incidente coreano que lhe deu (à Guerra Fria) uma dimensão militar e uma extensão planetária” (Aron, 1975: 76). Estabeleceu, na década de 1950, padrão de relacionamento caracterizado por fases mais tensas, períodos de relaxamento ou "coexistência pacífica". A morte de Stalin e o fim da Guerra na Coréia, em 1953, provocaram certa diminuição na tensão bipolar, mas nos anos subseqüentes, destaca-se principalmente a corrida armamentista. As duas superpotências adquiriram bombas de hidrogênio e novos vetores de lançamento, o que ampliou suas possibilidades de second strike e estabeleceu a chamada "destruição mútua assegurada", ou MAD. Episódios como o lançamento do Sputnik, em 1957, estabeleceram a percepção na administração, de que os Estados Unidos estariam perdendo a disputa tecnológica ${ }^{3}$. Assim, no fim dos anos 50, a conjuntura internacional desenvolvia-se em um sistema já bem estabelecido entre leste-oeste, com aparente vantagem para o bloco soviético.

Com a eleição de Kennedy, buscou-se superar a União Soviética, cujo governo de Kruschev se aproveitava da conjuntura favorável para pressionar os Estados Unidos em casos como o do U-2, em 1960, e na questão de Berlim. Desde o governo Eisenhower, havia pressão para o estabelecimento de um estatuto definitivo sobre a capital alemã, mas é com Kennedy que a tensão se elevará, em momentos como o de Checkpoint Charlie, em 1961, quando tanques americanos e soviéticos se posicionaram frente à frente e uma guerra parecia iminente.

3 Walker sobre a mensagem que o Sputnik enviava: the American homeland was now in pawn to superior Soviet Technology. Op. cit. p. 114. 
Havia também um novo elemento na confrontação bipolar: a Revolução Cubana. Seus movimentos iniciais também se deram anteriormente à administração Kennedy, mas foi a partir de 1961, que adquiriu contornos específicos da Guerra Fria. Junto com Berlim, a questão cubana tornou-se o principal problema dos norte-americanos no início da década de 1960, especialmente por se tratar de uma ameaça muito próxima fisicamente e que modificava os contornos da geografia da confrontação bipolar. Tratava-se de mais um elemento percebido como derrota ou desvantagem que os norteamericanos deveriam tratar com urgência. Cuba, assim, estava no centro da Guerra Fria.

A revolução de Fidel e seus desdobramentos, porém, continham também elementos específicos das relações interamericanas: marcava-se principalmente pela relação entre Estados Unidos e América Latina, cujas tendências históricas foram desenvolvidas nos séculos XIX e XX, e que adquiriram contornos específicos com a Guerra Fria.

Deve-se destacar que relações interamericanas anteriores à 1945, foram marcadas por constantes intervenções diretas dos Estados Unidos, principalmente na região caribenha, além de atuações indiretas, pressões econômicas ou favorecimento de determinados grupos políticos. A doutrina Monroe adquiriu novos contornos com o chamado Corolário Roosevelt e, nas primeiras décadas do século XX, países como Haiti, Costa Rica, República Dominicana e Panamá sofreram constantes intervençóes. Cuba talvez seja o país de mais destaque: sua independência teve atuação direta dos Estados Unidos, que adquiriram controle direto sobre o país pela Emenda Platt. Entre 1906 e 1922, ocorreram cinco intervençóes na ilha; mesmo quando os marines não desembarcavam, Cuba permanecia em grande medida controlada, o que se manteve até a revolução em 1959.

Ao mesmo tempo, a partir de 1889, com a I Conferência Interamericana, os Estados Unidos buscaram meios de cooperação. O objetivo inicial concentravase principalmente no comércio, mas a pressão dos latino-americanos direcionou as relações hemisféricas para aspectos políticos. Foram realizadas reuniōes no México (1901), Rio de Janeiro (1906), Buenos Aires (1910), Santiago (1923), e Havana (1928), que tratavam de assuntos como medidas relacionadas à paz, adoção de regras de arbitragem e relacionamento diplomático.

Os resultados foram, contudo, limitados, especialmente em razão das desconfianças contra os norte-americanos, que se recusavam a aderir ao princípio da não-intervenção. Essa adesão ocorreu apenas na conferência de Montevidéu, em 1933, que iniciou nova aproximação interamericana liderada por F. D. Roosevelt. Tratou-se da Política de Boa-Vizinhança, que durante a década de 1930, tinha como um de seus objetivos reforçar a segurança no continente contra as novas ameaças que surgiam, com destaque para a ascensão do nazifascismo. A aproximação foi reforçada em Buenos Aires, em 1936 (Conferência 
Interamericana de Consolidação da Paz), e em Lima, 1938; nesta, em meio às crescentes tensões na Europa, estabeleceu-se mecanismo de consultas que seria determinante na condução das relações interamericanas durante a guerra.

Talvez o grande exemplo de cooperação americana se deu na Segunda Guerra Mundial. Não só ocorreram diversas conferências (1939, 1940, 1942 e 1945), as quais contribuíram para o estabelecimento de uma posição comum (salvo a Argentina), mas se colocou em prática os mecanismos acordados, como no fornecimento de matérias-primas para os Estados Unidos ou na utilização de bases brasileiras como ponta de lança para a África.

A Conferência de Chapultepec, em 1945, marcou mais um passo na consolidação da parceria regional, visto que se estabeleceu o mecanismo de defesa coletiva das Américas, posteriormente institucionalizado no Tratado Interamericano de Assistência Recíproca (Tiar), 1947, e na Organização dos Estados Americanos (OEA), 1948. Quando do advento da criação desses institutos, a guerra já terminara, mas ainda se mantinha como o principal elemento organizador das relaçóes regionais.

Em certa medida, havia entre os Estados Unidos e as demais nações, visões diferentes sobre a cooperação (os norte-americanos viam os latinos apenas como fornecedores de matérias-primas), as quais eram eclipsadas pela urgência da guerra. Com o fim do conflito, divergências começaram a surgir. Esperavase a continuidade da "Política de Boa-vizinhança", o que não ocorreu devido à crescente tensão entre Estados Unidos e União Soviética. O imediato pós-guerra, assim, marcou-se tanto por iniciativas de cooperação importantes (como o Tiar e a OEA), quanto por um progressivo distanciamento de aspirações e interesses entre os países americanos; não se tratava de divergência profunda que causasse ruptura, mas foi responsável pelos problemas no relacionamento posterior.

A Guerra Fria deu nova configuração às relações interamericanas, especialmente com a Guerra da Coréia. Inicialmente, a região perdeu importância estratégica. Os Estados Unidos desviaram todos seus esforços para outras regióes, o que criou insatisfaçōes entre os latino-americanos. Perkings (1961:4), diagnosticava que, da perspectiva da segurança nacional, a América Latina encontrava-se em segundo plano. Segundo o autor, três razões justificavam essa visão: 1) os países da região permaneciam livres por mais de um século; 2) as repúblicas sentiam-se parte da civilização ocidental; 3) existiam fortes laços econômicos com os EUA.

É importante destacar que, em relação ao confronto mundial, a maioria dos governos latino-americanos apoiava os Estados Unidos, como se observou na IV Reunião de Ministros das Relações Exteriores de 26 de março a 7 de abril de 1951, em Washington, convocada para tratar da defesa comum contra as atividades do comunismo internacional. Em meio ao conflito coreano, os membros da OEA votaram uma resolução que considerava o comunismo forma de ameaça à paz. 
Posteriormente, ao longo da década de 1950, a política externa norteamericana desenvolveu a percepção de que o comunismo na região constituía ameaça real. Essa constatação moldou grande parte das iniciativas em relação à América Latina, fossem elas relacionadas à segurança ou ao desenvolvimento econômico. Foi determinante, também, para criar sérios erros de interpretação que confundiram revoltas nacionais com avanços da infiltração comunista. Isso se dava em razão do tipo de ameaça que se figurava no hemisfério ocidental: não se tratava de possibilidade de interferência direta da União Soviética no hemisfério ocidental, como se dava ao longo da Cortina de Ferro na Europa, mas sim, o perigo da organização de grupos (apoiados ou não pela URSS), que ameaçassem internamente a estrutura política de Estados da região. Assim, a agenda de segurança para o hemisfério era mais anti-subversiva do que anti-soviética ${ }^{4}$.

Em dois casos (anteriores à Cuba), esses elementos estiveram claros: em 1952, na Bolívia, e em 1954, na Guatemala. Em 1952, ocorreu revolução na Bolívia liderada por Paz Estenssoro. Após uma guerra civil que terminou em 1949, Estenssoro foi eleito em 1951 - mesmo exilado na Argentina - o que provocou a renúncia do presidente Mamerto Urriolagoitia e a ascensão da junta militar, com o propósito de impedir a posse de Estenssoro. Em 9 de abril, ocorreram insurgências em várias cidades bolivianas, com inúmeros mortos e feridos. Após intensos combates entre 9 e 11 de abril, a junta é derrubada e Paz Estenssoro chega ao poder. Dentre suas principais medidas, determinou a encampação de minas de estanho e iniciou programa de reforma agrária. A situação boliviana mobilizou atenções sobre suas reformas econômicas, principalmente dos Estados Unidos, interessados em proteger seus interesses comerciais e de suas empresas, e temerosos de possível infiltração comunista.

A base de apoio de Paz Estenssoro agrupava elementos de diferentes tendências ideológicas, tanto de direita, como de extrema esquerda - conforme telegrama da embaixada brasileira em La Paz (Moniz Bandeira, 1998: 108 ) o que motivou maior cautela por parte do governo dos Estados Unidos, na tentativa de evitar que o governo boliviano se radicalizasse. Bandeira cita outro memorando do embaixador brasileiro em La Paz, para quem o não reconhecimento poderia enfraquecer o governo revolucionário e deixar o país, em pleno coração da América, vulnerável ao comunismo internacional. A resolução do caso contou com importante mediação brasileira e a intervenção do irmão do Presidente Eisenhower, Milton Eisenhower, que percorrera a região em viagem de observação. Sua opinião no caso destacava a necessidade do Departamento de Estado não confundir qualquer movimento social com marxismo, toda reforma agrária com comunismo ou antiamericanismo com posição pró-soviética.

${ }^{4}$ Vide FERREIRA, Oliveiros. A Agenda interamericana pós Iraque. Perspectiva vista da América Latina. In: Seminário Internacional - As relaçôes Estados Unidos - América Latina no contexto da doutrina Bush. 15 e 16 de setembro de 2003. 
A moderação no caso boliviano, porém, não se refletiu no episódio seguinte, ocorrido na Guatemala. Medidas semelhantes de nacionalização foram adotadas no governo de Juan José Arévalo (1945-1950), o que levou seus inimigos a tentar caracterizá-lo como comunista. Conforme relata Gaddis Smith (1994: 72), em 1949, o Departamento de Estado iniciou uma guerra diplomáticoeconômica de baixa intensidade contra a Guatemala. Em 1951, Jacob Arbenz assume a presidência e amplia as políticas de Arévalo, principalmente o programa de reforma agrária que entrou em conflito com interesses da companhia norte-americana United Fruit.

Independentemente das causas, as atitudes de Arbenz foram vistas por muitos como indícios de infiltração comunista na América Central, especialmente pelo governo dos Estados Unidos, e motivaram a convocação da X Conferência Interamericana, realizada em Caracas, em 1954. Na reunião aprovou-se a chamada "Declaração de solidariedade para a preservação da integridade política dos Estados americanos contra a intervenção do comunismo internacional", cuja cláusula primeira condenava "as atividades do movimento comunista internacional, por constituírem intervenção nos assuntos americanos". O texto ainda recomendava a convocação de Reuniōes de Consulta previstas no Tiar para tratar de possíveis ameaças.

A resolução foi aprovada pela grande maioria dos participantes (Guatemala votou contra, e México e Argentina se abstiveram), mas, ao mesmo tempo em que condenava o comunismo, a resolução reforçou a necessidade de respeito ao princípio da não-intervenção, outra preocupação central para os latinoamericanos, mesmo antes da construção da OEA. A Declaração de Solidariedade, assim, concluía de forma a dar razão àqueles que viam na atitude dos governos latino-americanos uma clara definição de "Comunismo, não! Intervenção Ianque, também não!” (Ferreira, 1985). Há que se ressaltar o precedente jurídico fundamental que constituiu a reunião em Caracas: definiuse o comunismo internacional como ameaça à paz e à segurança hemisférica, incluindo-o dentre os eventos que justificariam a convocação de reunião de consulta do Tiar. A Reunião de Caracas será um dos pilares para a convocação da VIII Reunião de Consulta de 1962.

O caso da Guatemala terminou com a derrubada de Arbenz em 1954, a qual, contudo, desgastou o prestígio norte-americano ao reforçar desconfianças contra o "imperialismo" do norte. Ao mesmo tempo, estabeleceu modelo de ação para o governo dos Estados Unidos em eventos posteriores e, possivelmente, influenciou a operação da CIA, que culminou com a derrota na Baía dos Porcos em Cuba, 1961. Segundo Seyom Brown (1994: 106), a invasão da Guatemala a partir de Honduras, por Castillo Armas, financiada pela CIA, estabeleceu um modelo de ação para tratar de casos de subversão. O precedente de sucesso pode ser relacionado, dentre outros, à ação na Baía dos Porcos, em Cuba, 1961. 
A viagem de Nixon à América Latina e a criação da Operação PanAmericana (OPA) são os últimos pontos a se destacar. Nos fins da década de 1950, a insatisfação dos latino-americanos contra as atitudes norte-americanas ficou patente na visita do vice-presidente, Richard Nixon. Houve protestos em quase todos os locais visitados e algumas tentativas de agressão, principalmente em Caracas. Assim, em 1958, Juscelino Kubitschek enviou carta ao presidente Eisenhower, na qual propunha revisão nas relações hemisféricas e nos ideais do pan-americanismo. Conforme a análise de Alexandra de Mello e Silva (1992: 219), a OPA foi relevante ao relacionar o subdesenvolvimento à infiltração comunista. Mesmo sem o sucesso do projeto, a OPA serviu de inspiração para a Aliança, para o Progresso de Kennedy e, talvez o mais importante, reforçou a visão latino-americana sobre a ameaça comunista (relacionada ao desenvolvimento).

De forma resumida, portanto, é possível descrever o relacionamento dos Estados Unidos com a América Latina nos seguintes pontos: a) discrepância entre a preocupação com segurança e a contenção do comunismo por parte dos norte-americanos, e a aspiração ao desenvolvimento por parte dos latinoamericanos; b) os Estados Unidos confundiam o nacionalismo nascente na região com infiltração comunista, o que os levava a apoiar ditadores impopulares. Por sua vez, a América Latina ressentia profundamente o apoio norte-americano às companhias multinacionais e conseqüentes intervençōes, como no caso da Guatemala, que reforçavam a desconfiança contra o "imperialismo" do norte; c) em decorrência desses dois pontos, os países latino-americanos, apesar de posicionar-se contrários à ameaça comunista e apoiar os EUA no confronto mundial, defendiam a aplicação do princípio da não-intervenção nas relações hemisféricas (essa diferenciação será fundamental para se compreender a posição de alguns países em relação à Cuba).

Tem-se, assim, exemplos de expectativas e desconfianças nas relações regionais que perfazem o quadro político anterior à revolução liderada por Fidel Castro, verdadeiro ponto de inflexão. Pode-se dizer que os eventos descritos até aqui representam acontecimentos preliminares, que formaram as visões e os modelos de ação que influenciariam o tratamento da questão do comunismo no continente. Os desenrolares da Revolução cubana, por sua vez, obrigaram o sistema interamericano a "enfrentar um problema da Guerra Fria"5.

\section{A Revolução Cubana}

Muito já foi escrito sobre a revolução liderada por Fidel Castro, iniciada em 1959, e que resultou, dentre outras questōes, na VIII RMRE em Punta del Este, em 1962. O que importa destacar no presente é a reação das Américas

5 DANTAS, San Tiago. Discurso na Câmara dos Deputados. 17 de fevereiro de 1962. 
no caso e o que motivou a reunião aqui estudada. $\mathrm{O}$ ponto central, assim, é a relação entre Cuba e os comunistas. Conforme os exemplos anteriores demonstraram, os Estados Unidos reagiam, na América Latina, às reformas ou revoluçōes nacionalistas, confundindo-as muitas vezes com ameaças de subversão.

$\mathrm{O}$ início da revolução cubana repetiu em certa medida o caso da Guatemala, com encampações e estatizações que provocaram atritos com o governo norte-americano. Inicialmente, foi vista de forma positiva por grande parte dos países da região (mesmo nos Estados Unidos, segundo Kaplan\{1968: 259\}). As ações posteriores do governo revolucionário, todavia, criaram desconfianças sobre os rumos do movimento. Em 1960, apesar das suspeitas, documentos do Conselho de Segurança Nacional (memorando de 21 de junho de 1960, CIA Historical Review Program), demonstram que os norte-americanos não podiam confirmar se Castro era comunista ou não.

A indefinição era contrastada com os crescentes contatos entre autoridades cubanas e soviéticas, que culminou com a visita de Anastas Mykoyan em fevereiro de 1960, e o posterior convênio de venda de açúcar (reação aos cortes dos Estados Unidos). Em 1960, portanto, além dos atritos esperados entre um governo revolucionário latino-americano e os norte-americanos, tem-se a presença da União Soviética. As relações diplomáticas entre Estados Unidos e Cuba são rompidas em 3 de janeiro de 1961, ano em que ações mais diretas ganharam vulto. A ação na Baía dos Porcos foi séria derrota à administração Kennedy e provocou a declaração de Fidel sobre o caráter socialista da revolução, primeiro ponto importante na definição.

Há que se ressaltar que, durante todo o ano de 1961, os norte-americanos e alguns governos latino-americanos (como a Colômbia), buscaram convocar reunião de consulta para tratar da questão, mas havia resistência da maior parte dos governos, especialmente dos grandes Estados: Brasil, México e Argentina. Após o fracasso da Baía dos Porcos, a opção por uma resposta coletiva tornou-se necessária para os Estados Unidos. Volta-se, assim, para a relação do resto do hemisfério com Cuba.

Na América Latina, a mudança de simpatia para apreensão advinha especialmente das atitudes do governo revolucionário em relação aos países próximos a Cuba. Desde o início do movimento, as forças revolucionárias planejavam ultrapassar os limites da ilha caribenha, espalhando-se pela América Latina. Moniz Bandeira (1998: 192), relata que o próprio Che dissera que o futuro de Cuba estava relacionado à ampliação da revolução, e o método mais eficiente seria a luta de guerrilhas.

Cuba transformou-se, assim, em foco de irradiação de atividades guerrilheiras que provocaram instabilidade nos Estados da região, governados por ditaduras ou não. Os documentos da CIA ${ }^{6}$, de 1960 e 1961, mostram

${ }^{6}$ CIA Historical Review Program. 
crescentes infiltrações guerrilheiras em grande parte dos países da América Central, no Equador, Peru e Colômbia. Foram esses Estados os principais promotores das tentativas de convocação da reunião de consulta. Até dezembro de 1961, contudo, não se logrou a aprovação de uma RMRE.

A situação modifica-se completamente com a declaração de Fidel Castro, de 2 de dezembro de 1961, sobre sua vinculação ao marxismo-leninismo, a qual colocava Cuba diretamente no bloco soviético. A convocação de uma reunião de consulta tornou-se praticamente inevitável. Com a guerrilha avançando sobre países da América Latina, o governo da Colômbia havia pedido ao Conselho da OEA, em 10 de novembro de 1961, uma Reunião de Consulta prevista no Tiar. A convocação foi votada apenas em 4 de dezembro, subseqüente à declaração de Fidel. Aprovada por 14 votos a favor, 2 contra (Cuba e México), e cinco abstenções (Equador, Bolívia, Brasil, Chile e Argentina), a resolução estabelecia uma RMRE para 10 de janeiro de 1962, com o objetivo de analisar ameaças à paz e à independência política dos países americanos.

Iniciava-se a preparação para a VIII Reunião de Ministros das Relaçôes Exteriores, prevista inicialmente ${ }^{7}$ para 10 de janeiro de 1962, em Punta Del Este, Uruguai. A América Latina caminhou dividia para a reunião que assentaria a forma de tratamento do comunismo na região.

\section{A reunião de janeiro de 1962 e as principais decisões}

A preparação para a VIII RMRE foi marcada por grandes movimentações, em antecipação à reunião em si. Noticiava no Jornal do Commercio, em 10 de dezembro de 1961, que a futura conferência indicava possível rompimento com Cuba, sem, contudo, haver um consenso entre os membros da OEA. Alguns dias depois, o Diário de Notícias (de 19 de dezembro de 1961), ressaltava como as propostas ainda estavam se construindo, com o exemplo da delegação Colombiana, que o jornal indicava se limitar a pedir a Cuba o fiel cumprimento dos tratados vigentes.

A busca por sanções era patrocinada principalmente pelos Estados Unidos e os vizinhos da ilha, além de outros países que também sofriam com ações guerrilheiras supostamente patrocinadas por Cuba. Propunha-se tanto sanções econômicas e diplomáticas, quanto a possibilidade de uma ação armada; esta, porém, foi rapidamente descartada.

De outro lado, um grupo de países, liderados por México e Brasil ${ }^{8}$, mostrava-se contrário às sanções e advogava uma solução negociada. A posição brasileira exemplifica as razões desse grupo, estabelecida principalmente na alocução do Ministro San Tiago Dantas aos chefes de missão diplomática no

\footnotetext{
${ }^{7}$ Realizada em 22 de janeiro de 1962.

${ }^{8}$ A posição cubana, como seria esperado, era contrária à RMRE.
} 
Brasil, em 12 de janeiro de 1962. No documento, o chanceler admite que a evolução do regime revolucionário significava um profundo distanciamento de Cuba com os princípios americanos. Concordava, assim, com a necessidade de tratamento da questão. Afirmava, todavia, que "Qualquer ação internacional em relação a Cuba, daí resultante (da declaração do marxismo-leninismo de Fidel), para ser legítima e eficaz deve estrita observância aos princípios e normas de direito internacional e não pode deixar de ser orientada pelo propósito construtivo de eliminar os riscos eventuais, que a presença de um regime socialista no Hemisfério venha a apresentar [...] Fórmulas intervencionistas ou punitivas, que não encontram fundamento jurídico, e produzem, como resultado prático, apenas o agravamento das paixões e a exacerbação das incompatibilidades, não podem esperar apoio do governo do Brasil".

Em seu discurso, San Tiago desqualifica todas as possibilidades de sanção. A busca pela solução diplomática traduzia-se no que ficou conhecido como o projeto de "Finlandização de Cuba", ou seja, na sua transformação em Estado neutro, a partir de um "tratado de obrigações negativas". Essa proposta esteve presente em toda a reunião e tornou-se o centro da posição brasileira.

Percebe-se, então, que em grande medida a reunião se iniciara antes mesmo da data marcada, com posiçōes não muito flexíveis. Limitava-se seriamente as possibilidades de um consenso e criava-se a necessidade de novas idéias. Há que se ressaltar que não existia, nos discursos, referências diretas à suspensão de Cuba da OEA.

Marcada para 22 de janeiro, a Conferência iniciou-se efetivamente no dia 23, a pedido da delegação brasileira. De acordo com o Correio da Manhã de 23 de janeiro de 1962, esse adiamento foi aprovado por unanimidade, para que as delegaçóes tivessem mais um dia de consultas sem protocolo. Revela-se a intensidade dos contatos diplomáticos e, em certa medida, as dificuldades de consenso.

No dia 23, reuniram-se, assim, as delegações para a primeira sessão plenária no Hotel San Rafael, em Punta Del Este. Após a eleição do presidente e vicepresidente da conferência, tratou-se de questôes protocolares (credenciais, caráter público das reuniōes e comissão de estilo) e, por fim, marcou-se a primeira sessão para o dia seguinte, dia 24. Os principais temas da VIII RMRE foram discutidos na Comissão Geral, que teve nove sessōes, sem contar os encontros extraordinários, muitas vezes restritos apenas aos chanceleres e que buscavam solucionar os impasses.

Os discursos refletiam a já estabelecida divisão. Patrocinadora da reunião, merece destaque o discurso da Colômbia que, nas palavras de Jose Joaquin Caicedo de Castilla, pode ser visto como síntese da posição dos países latinoamericanos que defendiam sanções. O chanceler colombiano abriu a conferência e se pronunciou a favor de medidas contra Cuba. Com o propósito de preservação do sistema interamericano, ressaltou a necessidade de respeito ao princípio da 
igualdade e não-intervenção; exatamente esses princípios que justificariam a necessidade de sanções. Segundo Castilla, mesmo que a revolução cubana fosse aplaudida inicialmente, os rumos adotados desviavam-se dos ideais hemisféricos. O constante patrocínio cubano a mecanismos subversivos constituía o descumprimento do princípio da não-intervenção. Assim, a natureza do regime cubano e o patrocínio às guerrilhas justificavam a reunião de consulta e a adoção de sanções, na sua proposta, a ruptura de relações diplomáticas, consulares e econômicas, além da criação de um comitê de vigilância.

Pronunciando-se no mesmo dia de Castilla (24 de janeiro), o chanceler brasileiro, Francisco Clementino de San Tiago Dantas, representava o grupo que discordava de medidas punitivas. Em seu discurso, estabeleceu como os principais objetivos da reunião a preservação da unidade do sistema regional, a manutenção de seus princípios e o fortalecimento da democracia. Buscar a solidariedade continental não significava, contudo, a unanimidade a qualquer custo, ou sacrifício dos outros dois elementos. Na conjuntura da Guerra Fria característica permanente da realidade internacional - seria necessário encontrar uma nova forma de convivência com o Oriente (aqui se percebe claramente os princípios da PEI) e, na luta pela democracia dentro dessa realidade, seria necessário favorecer a preservação, robustecimento ou mesmo a "recuperação" de instituiçōes.

Em específico no caso de Cuba, não se negava que a adoção do comunismo era um problema para as relações hemisféricas, mas o melhor seria reaproximála do sistema, e não adotar medidas que levariam à opção ao bloco soviético. San Tiago sugere a criação de um tratado de obrigaçôes negativas, dentro do já mencionado projeto de "Finlandização". No mesmo sentido, retoma o discurso de 12 de janeiro, e critica a possibilidade de sançôes em razão de sua ineficácia.

Nos discursos de Caicedo Castilla e San Tiago Dantas percebe-se a utilização dos mesmos conceitos, mas com interpretaçōes diferentes sobre as possibilidades de ação. Os dois pronunciamentos revelam a permanência da divisão entre as nações latino-americanas e o impasse na reunião. Para muitos, novas fórmulas seriam necessárias.

No dia seguinte, na terceira sessão da Comissão Geral, pronuncia-se o secretário de Estado norte-americano, Dean Rusk, e uma nova possibilidade é levantada. Segundo Moniz Bandeira (1998: 365), o presidente Kennedy havia indicado na imprensa que poderia modificar a posição norte-americana, o que se refletiu no discurso do secretário de Estado.

Compartilhando, em parte, a visão de Castilla e San Tiago, Rusk afirma que os Estados Unidos simpatizavam com as aspirações de liberdade política e progresso social do povo cubano. Inaceitável era a filiação ao marxismoleninismo e o auxílio aos propósitos soviéticos, situação condenada previamente, na reunião de San José da Costa Rica, em 1960 (VII RMRE). O secretário de Estado exemplifica esse apoio cubano pelas votações nas Nações Unidas, nas 
quais Cuba havia sistematicamente posicionado-se com o bloco soviético. Postula, então: "Impulsado por esa fé marxista-leninista, el régimen de Castro se ha dedicado, no a luchar por la democracia dentro del Hemisferio ni siquiera en Cuba, sino a pervertir y corromper esa lucha para servir los intereses del comunismo internacional".

Rusk procura, assim, demonstrar a incompatibilidade do governo revolucionário, o que justificaria as seguintes medidas: reconhecimento da incompatibilidade; exclusão do regime de Castro da participação de órgãos e organismos do sistema interamericano, encomendando-se, ao Conselho da OEA, relatório que mostrasse a melhor maneira de dar rápido cumprimento à decisão; interrupção da venda de armas; criação de série de medidas defensivas, individuais e conjuntas, contra as diferentes formas de agressão política e indireta que se dirigiam contra o hemisfério. Dean Rusk termina seu discurso com referência à Guerra Fria: esta não se restringiria à contenda entre Estados Unidos e União Soviética; tratava-se de luta de todos, contra a tirania e pela liberdade. Especificamente, à reunião, nuestra misión actual no es la de permitir que um tiranuelo que há surgido entre nosotros nos aparte de estas grandes tareas, sino más bien ponerlo em su lugar y proseguir esta gran empresa em la que todos estamos empenados.

Tem-se, portanto, três discursos exemplificativos das posições adotadas pelos países americanos na VIII Reunião de Ministros das Relaçôes Exteriores. A posição cubana constituiria quarta vertente, representada pelo ministro Osvaldo Dorticós Torrado, que se pronuncia na tarde do dia 25 de janeiro. $\mathrm{O}$ discurso reflete a posição do governo de Castro durante toda a reuniāo, e nega a legalidade e a legitimidade das possíveis medidas que viriam a ser tomadas.

As discussōes continuam por mais cinco dias. No dia 30 de janeiro, a nona sessão da Comissão Geral inicia os procedimentos de votação dos dez projetos de resolução que haviam sido apresentados. Os projetos tratavam desde a celebração de eleições livres e reforma do estatuto da Comissão Interamericana de Direitos Humanos, até as medidas mais controversas, relacionadas à Junta Interamericana de Defesa e a participação do governo de Cuba em órgãos e organismos do sistema interamericano. A referência à suspensão do governo cubano da OEA (e não apenas de órgãos, conforme o discurso de Rusk), ocorrerá na plenária final, por meio de emenda.

As reuniōes da Comissão Geral terminam, assim, com a divisão entre os latino-americanos (o Haiti já mudara sua posição), sem as sanções inicialmente elaboradas, mas com a alternativa da suspensão. Na própria nona sessão, San Tiago expusera a ilegalidade da medida, por não estar prevista no art. $8^{\circ}$ do Tiar. Sua argumentação foi apoiada por outros cinco países e todos se abstiveram na votação.

Chega-se à questão da suspensão de Cuba da OEA. A autoria do projeto em si não é clara. Mesmo que fosse cogitado antes da reunião, os discursos não 
faziam referências à ele. Dean Rusk oficializa a possibilidade, mas Caicedo de Castilla (1970: 296), afirmou que a idéia foi colombiana. Arthur Schlesinger $\mathrm{Jr}$ (1965: 716), porém, indica que a proposta foi colocada pelos argentinos. A posição argentina era próxima à brasileira, mas havia urgência na busca por soluções intermediárias, principalmente por razões internas. Mesmo assim, no final, a Argentina manteve-se ao lado de Brasil e México.

O projeto de suspensão de Cuba da OEA (e da Junta Interamericana de Defesa), avançou sobre propostas como o tratado de obrigaçóes negativas, mesmo com as alegações brasileiras, dentre outras, de que a medida seria ilegal. Para aprová-la, necessitava-se de maioria de $2 / 3$, o que só foi conseguido com a mudança de posição do Haiti. Aqui também há uma controvérsia: diz-se que o Haiti mudou de posição por pressão norte-americana, que oferecia financiamentos em troca dos votos. Schlesinger Jr. afirma que foram os haitianos quem chantagearam os Estados Unidos. De qualquer forma, a posição haitiana foi modificada e a suspensão aprovada.

Há que se destacar que apenas a suspensão da OEA não conseguiu unanimidade. A declaração de incompatibilidade entre o regime cubano e os princípios do sistema, assim como a suspensão da JID, dentre outros, foram aprovados por unanimidade. A maioria dos países afirmaram posteriormente o sucesso da reunião e rogaram-se vitória sobre as outras propostas.

De uma certa forma, a reunião foi relativamente satisfatória. Sem qualquer incompatibilidade com a defesa da posição brasileira, a suspensão de Cuba possivelmente foi solução necessária para a manutenção da solidariedade continental. O sistema fora construído antes da Guerra Fria e, em 1962, era obrigado a tratar de um tema que não havia previsto. Houve um processo de adaptação à realidade internacional sem grandes prejuízos (mesmo que a solução tenha sido ilegal em relação ao Tiar), e estabeleceu-se bases mais sólidas para novas eventualidades. Apenas em 1964, votou-se sanções contra Cuba e modificou-se a Carta da OEA para prever a suspensão, mas Punta del Este tornou-se a base do sistema interamericano, por exemplo, no caso da crise dos mísseis de outubro de 1962. Criou-se mecanismos de ação na Guerra Fria; talvez esse tenha sido um dos méritos da VIII RMRE.

\section{Em buscas das razões brasileiras}

O problema ao projeto de suspensão de Cuba apontado em discursos de San Tiago Dantas, durante a reunião, foi sua ilegalidade. O Brasil questionara a própria convocação da conferência e, quando surgiu a proposta, mostrou-se inflexível na sua condenação. Do ponto de vista jurídico-institucional, a reunião de Punta del Este foi convocada legalmente, em razão dos precedentes estabelecidos na X Conferência Interamericana (1954), e na VII RMRE (1960). A natureza do regime cubano não poderia justificar sanções de qualquer forma, 
mas o patrocínio de guerrilhas na América Latina abria a possibilidade de punição. Não havia previsão no Tiar a suspensão de um país, o que tornou o ato de suspensão de Cuba contrário à letra do tratado. A reflexão jurídica, assim, favorece a posição que o Brasil adotou.

Não explica, todavia, as razóes que levaram a um posicionamento que condenou qualquer medida contra a ilha, que se manteve coerente nos discursos e propôs medidas alternativas na busca por uma solução negociada, mas que não votou negativamente à suspensão do governo de Fidel Castro, preferindo a abstenção. Oliveiros Ferreira (1985: 212), e Adolf Berle Jr (1962:103), oferecem elementos a partir dos quais parte este exercício de compreensão da política externa do evento. Segundo Ferreira, "para o Brasil, não era apenas o problema jurídico que estava em jogo. Era também a questão de afirmar posição que não discrepasse da de Quadros, para não dar a impressão de subserviência aos Estados Unidos". Berle, por seu turno, afirma que "a crucial fact was that several of the six governments abstaining from voting on the resolution excluding the Castro regime from the Inter-American councils did so not because of inherent disagreement, but because their internal situation was such that their governments felt they could not act".

A participação brasileira na VIII RMRE deve ser entendida como a intersecção entre um projeto de política externa claramente delimitado no governo Jânio Quadros, que definiu uma linha política para o caso cubano em 1961, e que foi mantido por Goulart no início de 1962, mais exigências do quadro político doméstico após a crise da renúncia, caracterizado pela radicalização política. Assim, a Política Externa Independente (PEI), teve em Cuba um desafio concreto e a utilizou, possivelmente, como vitrine de atuação. Sua liberdade de movimento, porém, estava seriamente limitada pela controvérsia interna.

Formulada pelo presidente Jânio Quadros e seu chanceler, Afonso Arinos, a PEI adquiriu essa designação posteriormente, já na gestão de San Tiago Dantas. Mesmo assim, convencionou-se denominar todo o período com a expressão "Quadros-Goulart", devido à continuidade que se pôde observar. Os princípios fundamentais da PEI foram publicados em artigo de Quadros para a Foreign Affairs de agosto de $1961^{9}$.

O presidente Jânio Quadros destaca a dimensão e a força do crescimento populacional e do potencial econômico do país, e afirma que o Brasil deixara de seguir uma linha subsidiária para perseguir efetivamente seus interesses. $\mathrm{O}$ principal desses interesses centrava-se no desenvolvimento econômico; este orientava a política externa, a partir da busca por se tornar independente da Guerra Fria, aproveitando assim todas as oportunidades que fossem oferecidas. Reafirma a ligação brasileira com o mundo ocidental, com a prioridade da

9 Publicado também na Revista Brasileira de Política Internacional de dezembro de 1961 
democracia (fala da associação brasileira ao bloco ocidental), o reconhecimento da legitimidade da luta pela liberdade econômica e política. Não deixa de reconhecer que o socialismo não interessa aos países latino-americanos, mas, dada a pobreza que assolava a região, ele poderia avançar. Percebe-se, assim, a relação que o autor faz entre o desenvolvimento econômico e o enfrentamento da ameaça comunista, retomando, de certa forma, o argumento central da OPA.

O princípio de ação retirado dessa definição consistia em impedir que a confrontação ideológica afetasse as possibilidades de crescimento que o país tanto necessitava. Conforme afirmou a Mensagem ao Congresso Nacional de 1961 10: "O Brasil só pode ver a causa ideológica condicionada por seu caráter nacional e seus interesses legítimos. $\mathrm{O}$ grande interesse brasileiro, nesta fase histórica, é o de vencer a pobreza, o de realizar efetivamente seu desenvolvimento. O desenvolvimento e a justiça social são da essência mesma dos ideais democráticos".

Salienta Clodoaldo Bueno (2002: 310), que a política de Jânio Quadros, mesmo que possuísse um importante componente regional, partia de uma concepção universal e se caracterizava essencialmente por seu pragmatismo. Buscava promover os interesses nacionais, adotando uma posição independente (e não neutralista, segundo o presidente), perante outras nações, sendo que um dos elementos fundamentais caracterizava-se pela busca por desenvolvimento dentro de um quadro internacional específico. A Guerra Fria separava as nações em blocos, o que limitava a margem de ação, principalmente em relação aos mercados; por exemplo, o Brasil ficava limitado majoritariamente à Europa e aos Estados Unidos. O termo "independente", portanto, talvez possa ser utilizado tanto como uma afirmação da ruptura com linhas anteriores da Política Externa Brasileira, quanto como uma declaração em relação à Guerra Fria, de "independência" da disputa ideológica.

Poucos eventos conjugaram os desafios da PEI como Cuba. Conforme apontado na primeira parte do presente trabalho, no início da década de 1960, Cuba era (junto com Berlim), elemento de grande tensão da disputa ideológica entre Estados Unidos e a União Soviética. Para um país que buscava a independência ideológica, a atuação nesse caso seria praticamente uma "vitrine", principalmente para os países do bloco oriental.

Havia, também, as variáveis regionais e as tendências históricas do relacionamento interamericano, que inspiravam a busca pela não-intervenção e soluções negociadas contra ações intervencionistas, as quais poderiam abrir precedentes (talvez até contra atitudes como a PEI). Finalmente, tinha-se a diplomacia entre Brasil e Estados Unidos, sobre a qual se buscava imprimir um relacionamento mais igualitário (e não mera oposição), mas cujas repercussões no Brasil, dividiam a opinião pública. Assim, a questão cubana

${ }^{10}$ In: ARINOS, Filho. Diplomacia Independente. p. 156. 
possivelmente consistiu num dos maiores testes da PEI, o que destaca a importância da VIII RMRE.

A construção da política de Jânio Quadros em relação à Cuba iniciou-se ainda na campanha presidencial, em visita que o então candidato fez, junto com Arinos em 1960. Segundo as considerações deste (2001: 129), a questão passaria pela revitalização da ONU e da OEA, com a reintegração de Cuba ao sistema, processo cuja mediação brasileira poderia ser útil. Já nesse momento, Arinos tratava de se evitar "jogar" os cubanos para o bloco oriental.

Até 1961, as relações das Américas com Cuba ainda não haviam entrado em fase mais aguda. O governo JK via a Revolução Cubana sob o prisma da Operação Pan-Americana e o relacionamento com os Estados Unidos. Nas reuniōes interamericanas, principalmente na VII RMRE (em 1960) - na qual se condenou o comunismo sem referências diretas a Cuba - em tendência mais próxima aos Estados Unidos. Não assumiu, contudo, apoio completo ao governo Eisenhower, defendendo, dentre outros, o princípio da não intervenção e a busca por uma solução pacífica ${ }^{11}$.

Foi no governo Jânio Quadros que o Brasil construiu um plano mais elaborado para o tratamento do tema. Com a radicalização do conflito, ocorreram várias gestóes do governo norte-americano, fosse para pressionar por uma reunião de consulta, ou um posicionamento contrário a Castro, fosse para pedir a ajuda brasileira em uma solução negociada ${ }^{12}$. De uma dessas consultas (25 de abril), resultou memorando de 2 de maio de 1961 (Arinos, 2001: 179), do chanceler para o presidente, no qual se aprofunda a questão e se define linhas de ação.

O chanceler afirma que, dada a capacidade de os Estados Unidos conseguirem apoio de outros governos para uma reunião de consulta, o Brasil não deveria deixar de comparecer, principalmente em razão de sua importância no continente. Em questão, encontravam-se, na visão do ministro, duas teses aparentemente antagônicas: a solidariedade continental e a não-intervenção. $\mathrm{O}$ ponto mais sensível talvez fosse a posição norte-americana, que parecia ao chanceler decidida à ação diplomática e jurídica (sançôes), até porque uma intervenção sem cobertura legal lhe criaria uma situação extremamente grave (como de fato ocorreu com a Baía dos Porcos).

Com esse pressuposto, afirmou-se que duas linhas de ação eram possíveis ao Brasil: na primeira, evitar-se-ia a condenação do comunismo, mas o resultado não seria profícuo, visto que isolaria o país no continente, além de efeitos danosos com relação à opinião pública interna. Por outro lado, a possibilidade de apoiar uma intervenção em Cuba poderia afetar a linha de independência

\footnotetext{
11 Documento de 24 de novembro de 1960, assinado por Vasco Leitão, apontava uma possibilidade de diminuição da tensão entre Cuba e EUA. Embaixada dos Estados Unidos do Brasil em Cuba, telegrama no 255/920. (24h)(22). Arquivo Ministério das Relações Exteriores.

12 Informe da chancelaria brasileira ao ministro Arinos. In : ARINOS, Filho. p. 175
} 
da política externa, que tinha como pontos fundamentais o apoio ao princípio da não-intervenção e à luta anticolonialista. Acreditava-se, assim, que "com habilidade e boa-fé", o país conseguiria entrosar as regras de direito e manter uma defesa coerente da solidariedade interamericana. Diante da constatação de que caso Cuba radicalizasse sua posição, os Estados Unidos interviriam, disse Arinos (Arinos Filho, 2001: 175): "Então, nós nos oporíamos à intervenção em Cuba, feita a pretexto de prevenir a América contra a intervenção do comunismo internacional. Mas, ao mesmo tempo, nós concordaríamos com todas as medidas preventivas que visassem evitar os riscos que o comunismo traria a certos países mais expostos da América do Sul [...], os quais, realmente, ficarão em sérios apuros, caso se consolide, em Cuba, um fidelismo comunista. Faríamos algo como o cordão sanitário que cerca a Alemanha oriental".

Esse posicionamento permaneceu durante todo o governo de Jânio Quadros ${ }^{13}$, tanto na condenação ao episódio da Baía dos Porcos, quanto na tentativa do Brasil de auxiliar as partes a chegarem a um acordo, como ocorreu no episódio relatado por Roberto Campos, entre Che Guevara e o embaixador norte-americano, na Conferência de Punta Del Este de agosto de 1961, poucos dias antes da renúncia do presidente.

A política desenvolvida por Jânio Quadros foi mantida na solução parlamentarista do governo de João Goulart. O programa de governo apresentado pelo presidente do Conselho de Ministros, Tancredo Neves, à Câmara dos Deputados ${ }^{14}$, mantinha as linhas da PEI, lideradas agora pelo chanceler San Tiago Dantas. A continuidade fica patente na conhecida reunião da "Casa das Pedras". Reuniram-se diplomatas, políticos e especialistas, grande parte nomeados ainda no governo Jânio, para discutir diversos assuntos da agenda externa, principalmente Cuba. $\mathrm{Na}$ mesma linha do memorando de Afonso Arinos, Vasco Leitão da Cunha propôs o que ficou chamado de projeto de "Finlandização" de Cuba, consubstanciada no tratado de obrigações negativas. Isso não significava a aceitação de um regime comunista (as autoridades brasileiras condenavam-no unanimemente); centrava-se na garantia cubana de não contrair alianças militares, limitar suas compras de armas e abster-se de propaganda política nos vizinhos (criando uma situação semelhante a da Finlândia). San Tiago Dantas aprovou o plano imediatamente, cujas linhas gerais foram expressas na alocução de 12 de janeiro de 1962.

Em Punta del Este, assim, o Brasil, em grande medida, manteve posição coesa, a partir de planos elaborados ao longo de 61. O Brasil buscava uma forma de atuação internacional que, ao mesmo tempo em que defendia valores como a democracia ocidental, permitia o contato e negociação com outros blocos. A independência significava a diminuição da influência do confronto

13 Discursos de Arinos na Câmara dos Deputados. 17 de maio, 6 de junho e 28 de julho.

14 In: DANTAS. 1962. p. 17. 
ideológico na formulação da política externa. Isso constituiu ponto essencial para a posição brasileira na VIII Reunião.

Houve, porém, contradições. Se, por mais que fosse ideal, o tratado de obrigações negativas encontrava resistência nos próprios cubanos - o que inviabilizava-o - por que manter o posicionamento e não aceitar medidas mais enérgicas? Por outro lado, se se vislumbrava a possibilidade de aplicação do tratado e a mediação entre Cuba e o hemisfério, por que houve abstenção, e não se votou contra a resolução que suspendia o governo revolucionário?

As respostas a essas indagações possivelmente se encontram no segundo ponto de influência da política externa brasileira para a época, a questão interna. Desde o início da Revolução Cubana, em 1959, a visão dos atores domésticos dividia-se, em grande medida, pela própria polarização no país. Segundo Skidmore (2000: 18), no fim da década de 1950 e início dos anos 1960 , o Brasil viu-se em profunda crise institucional, "resultante do fracasso em criar instituições e processos políticos que pudessem canalizar e dirigir as rápidas mudanças sociais e econômicas que transformaram o Brasil, desde 1930". O governo de Jânio enfrentou graves problemas, políticos e econômicos, os quais podem ser relacionados, por exemplo, aos motivos que levaram à criação da PEI.

A própria execução da PEI, especialmente no caso de Cuba, causava controvérsias. José de Brito Cruz (1989: 70), afirma que um dos objetivos da PEI era de âmbito interno, de cooptar setores da esquerda para um governo originário de uma coalizão conservadora. Não era possível, porém, desconsiderar a oposição anticomunista, o que o próprio chanceler Arinos revela em memorando (2001: 128), elaborado após a visita do embaixador Cabot.

Talvez seja importante retomar as consideraçóes iniciais sobre a PEI. Mesmo que Jânio buscasse cooptar a esquerda, é mais provável - pelos discursos - que a política externa buscava efetivamente isolar-se da disputa ideológica, favorecendo interesses nacionais, com qualquer dos blocos. $\mathrm{O}$ resultado mais imediato, porém, foi principalmente a oposição dos dois lados. Um dos eventos mais reveladores dos problemas internos da PEI foi o episódio da condecoração de Che Guevara. Provavelmente, resultado de uma intermediação de Jânio entre Cuba e a Santa Sé, ocorreu pouco antes da renúncia e atraiu ainda mais atenção para a questão cubana.

Tem-se, em seguida, a crise da posse e as questôes da ascensão do presidente João Goulart. Mais uma vez, conforme Brito Cruz (1989: 71), o governo Goulart nasce sobre o "signo da suspeição ideológica". A continuidade da linha adotada por Jânio, assim, torna-se mais difícil, especialmente às vésperas da VIII RMRE. Mesmo setores mais moderados entram no debate, como foi o caso da carta publicada por quatro ex-chanceleres, a qual pedia medidas mais enérgicas em relação ao governo Castro. Mario Gibson Barbosa (1992), relata que a proposta brasileira tinha o apoio de vários setores da esquerda, mas ele se tornava incômodo por polarizar a questão. 
As pressões internas são observadas claramente nas instruções do Conselho de Ministros à delegação brasileira. O documento afirma que o Brasil não votaria sanções contra Cuba, pois essas medidas apenas serviriam "para agitar a opinião pública e radicalizar ainda mais a política interna do Brasil”. Tanto os relatos de Arinos e Gibson Barbosa, quanto reportagens da época (por exemplo, artigo do Correio Paulistano de 20 de janeiro), demonstram a clara influência dos eventos internos na posição brasileira em Punta del Este.

Talvez o principal efeito das pressões domésticas tenha sido o de limitar as opções da delegação e não modificar sensivelmente a linha de ação traçada ainda no governo Jânio. $\mathrm{O}$ Brasil manteve uma posição consistente com os princípios da PEI e ganhou a simpatia de diversas delegações e setores da imprensa ocidental, como o caso do New York Times e The Economist. O apego inflexível ao Direito, porém, pode tanto significar a consistência do respeito brasileiro às regras interamericanas, quanto a tentativa de utilizar-se de argumentos neutros, sobre os quais nenhuma posição ideológica poderia se sobrepor. Assim, se é possível que a posição contrária à suspensão de Cuba tenha se dado pelo respeito às normas, especialmente do chanceler brasileiro, pode ser que buscasse se isolar da decisão; conforme o relato de Oliveiros Ferreira no início deste trabalho, a questão jurídica não era impossível de ser resolvida.

A abstenção brasileira sobre suspensão de Cuba da OEA refletia, de certa forma, a necessidade de minimizar controvérsias internas. Ao mesmo tempo, aprovou-se a suspensão cubana da Junta Interamericana de Defesa. Essas duas votaçôes possivelmente indicam o desejo de atender às reivindicaçôes diversas, da esquerda (abstenção à suspensão), e da direita (sim na suspensão da JID). Não se pode esquecer, conforme Gibson Barbosa, que o presidente Goulart chegou a mudar de posição em razão da pressão norte-americana, mas a modificação não se concretizou devido à recusa do chanceler em atender a ligação, pouco antes da sessão final.

Na volta ao Brasil, San Tiago enfrentou problemas (em debates na Câmara), e provavelmente sua atuação em Cuba influenciou negativamente a sua indicação a primeiro-ministro. Mesmo assim, a política adotada somente foi alterada com o golpe de 1964.

A posição brasileira em Punta del Este pode ser entendida, assim, como o resultado de um projeto de política externa traçado em razão das necessidades do país dentro de uma conjuntura internacional específica, no qual destacavase o problema cubano. Cuba conjugava diversos elementos da realidade internacional e tornava-se uma espécie de vitrine para a demonstração do novo posicionamento do país. Era necessário encontrar uma solução negociada, dentro dos princípios da $\mathrm{PEI}$, mas elementos domésticos limitavam a participação nacional. O resultado da VIII RMRE, mesmo sem a prevalência completa da visão brasileira, foi relevante na concretização dos princípios e idéias contidos 
nos discursos que instituíram a PEI e na revelação dos seus limites - domésticos e internacionais.

\section{Conclusão}

No presente trabalho se procurou analisar a posição brasileira na VIII RMRE, a qual, dentre outras medidas, suspendeu o governo de Fidel Castro da OEA. Para tanto, procedeu-se à contextualização da questão e o caminho percorrido até a aprovação e início da conferência, em janeiro de 1962. Em seguida, analisouse a reunião, seus argumentos e resultados. Com todos os elementos gerais estabelecidos, estudou-se a política externa brasileira. Cabe, talvez, voltar ao questionamento inicial do embaixador Teixeira Soares, sobre o mérito da reunião.

Uma visão positiva da VIII RMRE é possível tanto do ponto de vista do sistema (que favoreceu a suspensão), quanto da posição brasileira: a conferência atingiu resultados satisfatórios, a partir de uma visão do contexto da Guerra Fria (sua escalada na região), e a necessidade de manutenção da solidariedade continental; exatamente essa questão do conflito global interferindo no plano regional (ou mesmo doméstico), que o Brasil buscava superar, neutralizando o conflito ideológico, por exemplo, pela "Finlandização" de Cuba. Portanto, a política externa brasileira traduzida na proposta de Punta del Este, talvez fosse a mais eficaz para a América Latina, por afastar-se do conflito ideológico e abrir espaço para o tema do desenvolvimento. Como isso não foi possível, o resultado foi satisfatório se observado dentro da conjuntura mundial. Nesse sentido, talvez seja possível afirmar que o resultado da VIII RMRE foi um second best.

Há também a relação entre o evento e as mudanças na política externa brasileira. A reunião demonstrou a força e os limites da PEI. Talvez este tenha sido, em relação à política externa brasileira, o maior mérito da Conferência de Punta del Este de janeiro de 1962.

Recebido em 11 de abril de 2005 Aprovado em 10 de setembro de 12005

\section{Referências bibliográficas}

AMOROSO LIMA, Alceu. A Posição do Brasil em Punta del Este. in: Revista Brasileira de Política Internacional. ano V, n. 17. Rio de Janeiro: Instituto Brasileiro de Relações Internacionais. Mar, 1962.

ARCHER, Renato. San Tiago e a Política Externa Independente. In: San Tiago - vinte anos depois. José Vieira Coelho et al. Rio de Janeiro: Paz e Terra, 1985.

ARINOS, Filho, Afonso. Diplomacia Independente: um legado de Afonso Arinos. São Paulo: Paz e Terra, 2001. 
ARON, Raymond. A República Imperial: os Estados Unidos no Pós-Guerra. Rio de Janeiro: Zahar, 1975.

BARBOSA, Mário Gibson. Na Diplomacia, o traço todo da vida. Rio de Janeiro: Record, 1992.

BERLE, Adolf A.. Latin América. Diplomacy and Reality. New York: Harper Colophon, 1962.

BROWN, Seyom. The Faces of Power: constancy and change in United States Foreign Policy from Truman to Clinton. New York: Columbia University Press, 1994.

CAMPOS, Roberto. A Lanterna na Popa: memórias. Rio de Janeiro: Topbooks, 1994.

CASTILLA, Jose Joaquin Caicedo. El derecho internacional en el Sistema Interamericano. Madrid: Ediciones Cultura Hispanica, 1970

CERVO, Amado Luiz. BUENO, Clodoaldo. História da Política Exterior do Brasil. Brasília: Editora UnB, 2002.

Amado Luiz. Latin America and the Cold War. In: Coluna Além do Quadro Negro. Disponível em: <http://www.relnet.com.br>.

CRUZ, José Humberto de Brito. Aspectos da evolução da diplomacia brasileira no período da política externa independente (1961-1964). In: Ensaios de História Diplomática do Brasil (1930-1986). Introdução de Rubens Ricupero e seleção, organização e edição de Sérgio Danese. Brasília: FUNAG/IPRI, 1989.

DA CUNHA, Vasco Leitão. Diplomacia em Alto-Mar. Depoimento ao CPDOC. 2a . Edição. Rio de Janeiro: Editora FGV, 2003.

DANTAS, San Tiago. Politica Externa Independente. Rio de Janeiro: Editora Civilização Brasileira, 1962.

FERREIRA, Oliveiros S. Cuba, ou o desafio da Dívida Externa. In: Política e Estratégia, vol. III, n. 2. abr/jun 1985.

KAPLAN, Lawrence S. Recent American Foreign Policy: conflicting interpretations. Illinois: The Dorsey Press, 1968.

MELLO E SILVA, Alexandra. Desenvolvimento e Multilateralismo: um estudo sobre a Operação Pan-Americana no contexto da política externa de JK. In: Contexto Internacional, Rio de Janeiro, vol. 14, n. 2, jul/dez 1992.

MONIZ BANDEIRA, Luiz Alberto. De Martí a Fidel: a Revolução Cubana e a América Latina. Rio de Janeiro: Civilização Brasileira, 1998.

PERKINGS, Dexter. The United States and Latin América. Baton Rouge: Louisiana State University Press, 1961.

QUADROS, Jânio. Nova Política Externa do Brasil. In: Revista Brasileira de Política Internacional. Ano IV, n. 16. Rio de Janeiro: Instituto Brasileiro de Relações Internacionais, 1961.

SCHLESINGER JR., Arthur. A Thousand Days: John F. Kennedy in the White House. Greenwich: Fawcett Publications Inc, 1965.

SKIDMORE, Thomas. Brasil: de Getúlio a Castelo. 12a . ed. São Paulo: Paz e Terra, 2000.

SMITH, Peter H.. Talons of the Eagle: dynamics of US - Latin American relations. $2^{\text {nd }}$ Edition. New York, Oxford: Oxford University Press, 2000.

TEIXEIRA SOARES, Emb. O Brasil no conflito ideológico global (1937-1979). Rio de Janeiro: Civilização Brasileira, 1980. 
VASQUEZ, Modesto Seara. Tratado General de la Organización Internacional. México: Fondo de Cultura Económica, 1974.

WALKER, Martin. The Cold War. Vintage, 1993.

WEFFORD, Francisco. O Populismo na política brasileira. 2a . ed. São Paulo: Paz e Terra, 1980.

\section{Resumo}

Considerada por San Tiago Dantas como "uma reunião que marcou época na formação do americanismo", a Conferência de Punta del Este, de janeiro de 1962, dedicou-se a tratar dos efeitos da Revolução Cubana no hemisfério. Declarou-se a incompatibilidade do comunismo com os princípios americanos e suspendeu-se Cuba da Junta Interamericana de Defesa (JID) e da OEA. A participação brasileira teve grande destaque e repercussão tanto interna quanto internacionalmente. Procura-se analisar as razões que levaram o Brasil a adotar a posição de condenar o comunismo cubano e aprovar a suspensão de Cuba da JID, sem, porém, concordar com sua suspensão da OEA.

\section{Abstract}

Considered by San Tiago Dantas as "a landmark meeting for the formation of Americanism", the Conference of Punta del Este of January 1962 dealt with the effects of the Cuban Revolution on the Hemisphere. A resolution was approved declaring the incompatibility of communism with American principles, suspended Cuba from the Inter-American Defense Board (IDB) and from the Organization of American States (OAS). The Brazilian participation gained high distinction and had repercussions not only domestically but also internationally. The present work seeks to analyse the reasons that led Brazil to condemn communism in Cuba and approve the suspension of this country from the IDB, without, however, agreeing to the suspension of Cuba from the OAS.

Palavras-chave: Conferência de Punta del Est - Política Externa - Brasil Key words: Conference of Punta Del Est - Foreign Affairs - Brazil 